\title{
Self-Assembled Gyroidal Mesoporous Polymer-Derived High Temperature Ceramic Monoliths
}

\section{Supporting Information}

\author{
Ethan M. Susca ${ }^{\dagger}$, Peter A. Beaucage ${ }^{\dagger}$, Margaret A. Hanson ${ }^{\S}$, \\ Ulrike Werner-Zwanziger $^{\S}$, Josef W. Zwanziger ${ }^{\S}$, Lara A. Estroff ${ }^{\dagger, \varnothing}$, Ulrich Wiesner ${ }^{\dagger, *}$ \\ ${ }^{\dagger}$ Cornell University, Department of Materials Science and Engineering, \\ 214 Bard Hall Ithaca NY 14853, USA \\ ${ }^{\S}$ Dalhousie University, Department of Chemistry, \\ 6274 Cobourg Rd, Halifax NS B3H 4R2 Canada \\ ${ }^{ø}$ Kavli Institute at Cornell for Nanoscale Science, Ithaca, NY 14853, USA
}

\section{List of Supporting Information Figures and Proceedures}

S1: Monolithic materials with and without $450{ }^{\circ} \mathrm{C}$ anneal step or structure-directing triblock terpolymer......................................................

S2: Attenuated Total Reflectance Fourier Transform Infrared Spectroscopy (ATR-FTIR)

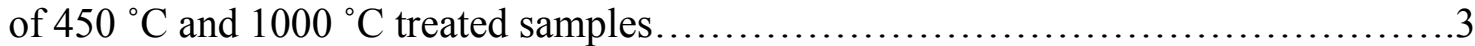

S3: Electron microscopy and FFT insets of samples processed to temperatures of

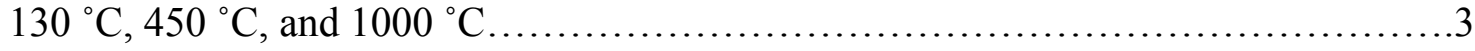

S4: Low-magnification scanning electron micrograph of mesoporous gyroidal silicon oxynitride ceramic................................................4

S5: X-ray diffraction spectrum of mesoporous gyroidal silicon oxynitride ceramic.....5

S6: Calculation of porosity from specific pore volume and density..................5

Additional Methods...............................................................

Supporting Information References........................................... 7 


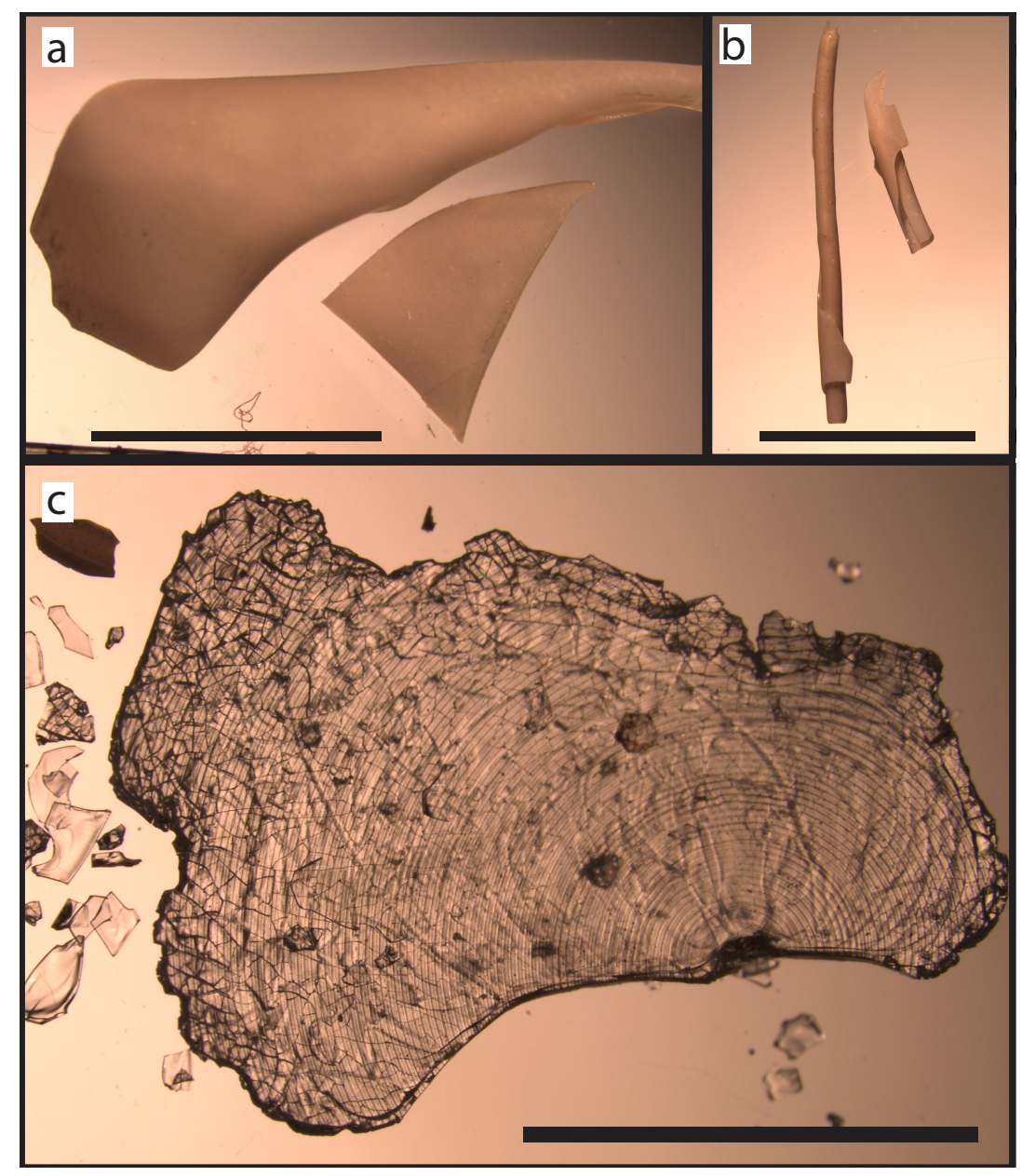

Figure S1. Gyroidal SiON (a, b) versus unstructured (ISA-free) SiON (c) derived from PMVS. Processing for (b) occurred without the intermediate $450{ }^{\circ} \mathrm{C}$ pyrolysis under nitrogen forming gas, while (a) had both thermal treatments applied as described in the main text. The difference between (a) and (b) illustrates the importance of the $450{ }^{\circ} \mathrm{C}$ step in retaining macroscopic structure by preventing film rollup. Films in (b) have been processed in an otherwise identical manner as those in (a, c) through evaporation from $5 \mathrm{wt} \%$ precursor solution in toluene (as described in the main text), crosslinking, and pyrolysis. Unstructured PMVS film (c) without use of the terpolymer ISA and processed to $1000{ }^{\circ} \mathrm{C}$ under ammonia resulting in significant macropore formation, cracking, and fracture. In contrast, ISA-structured ceramics appear smooth $(a, b)$. It should be noted that the poor monolith formation for neat PMVS processed in ammonia, similar to (c), has been previously reported elsewhere. ${ }^{1}$ Semicircular ring patterning is a fingerprint from the mill lines at the bottom of the Teflon dish used to evaporate the material from solution. All scale bars are $5 \mathrm{~mm}$. 


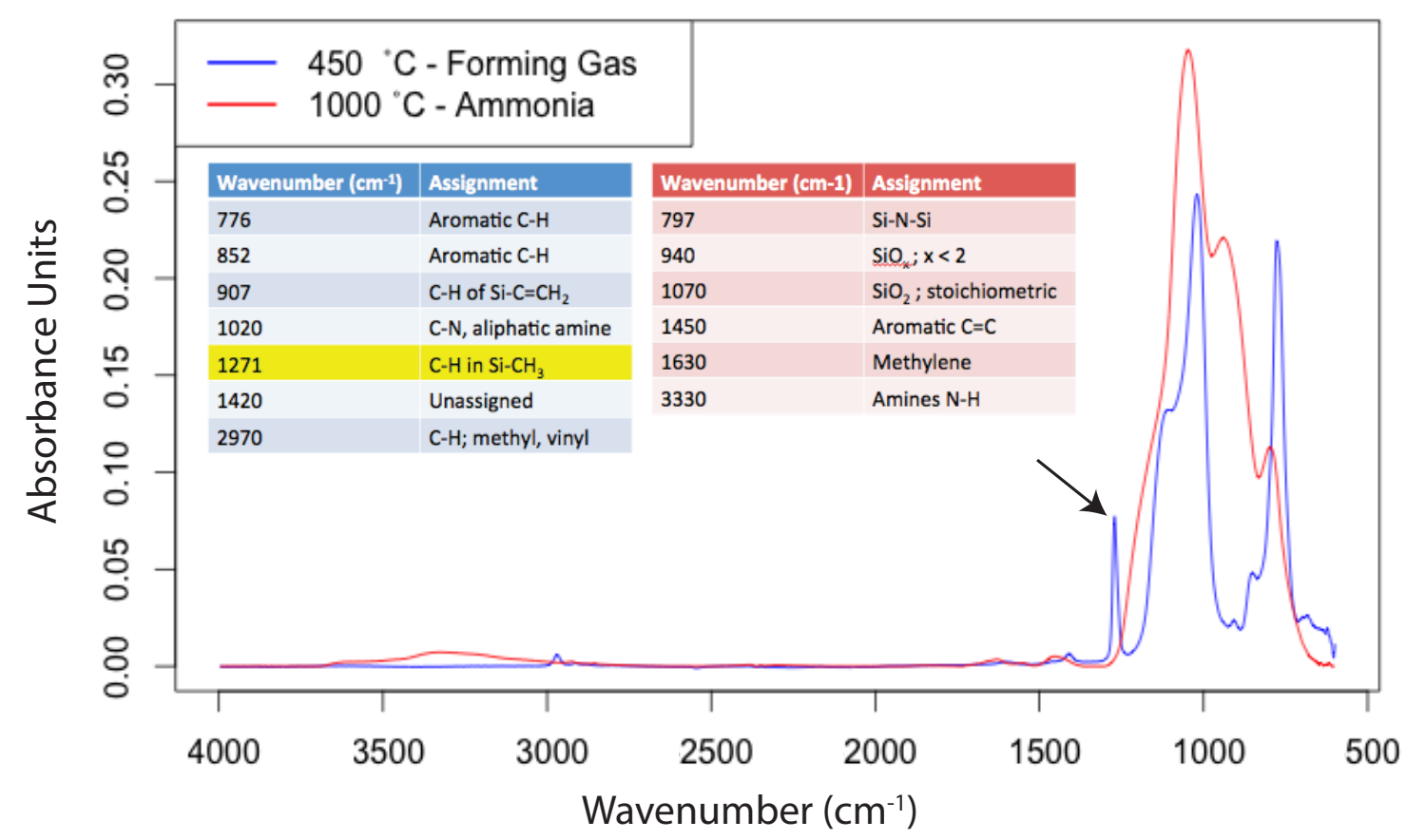

Figure S2. Attenuated Total Reflectance Fourier Transform Infrared Spectra (ATR-FTIR) acquired for ball-mill powderized samples after $450{ }^{\circ} \mathrm{C} /$ forming gas (blue trace) and $1000{ }^{\circ} \mathrm{C} /$ ammonia (red trace) pyrolysis steps. Traces are background subtracted. The red trace in the fingerprint region shows peaks characteristic of $\mathrm{SiO}_{\mathrm{x}} \mathrm{N}_{\mathrm{y}}$, as described elsewhere. ${ }^{2}$ While the left side of the spectra (above $2500 \mathrm{~cm}^{-1}$ ) don't show strong specific carbon signals, the peak at $1271 \mathrm{~cm}^{-1}$ (arrow) of the sample treated to $450{ }^{\circ} \mathrm{C}$ under forming gas can be assigned with high confidence to the symmetric $\mathrm{CH}_{3}$ stretching vibration from a methyl-silicon bond ${ }^{2}$ and is consistent with methane evolution reported above $450^{\circ} \mathrm{C}$ (around $570{ }^{\circ} \mathrm{C}$ ) in the condensing silazane network. ${ }^{1-4}$

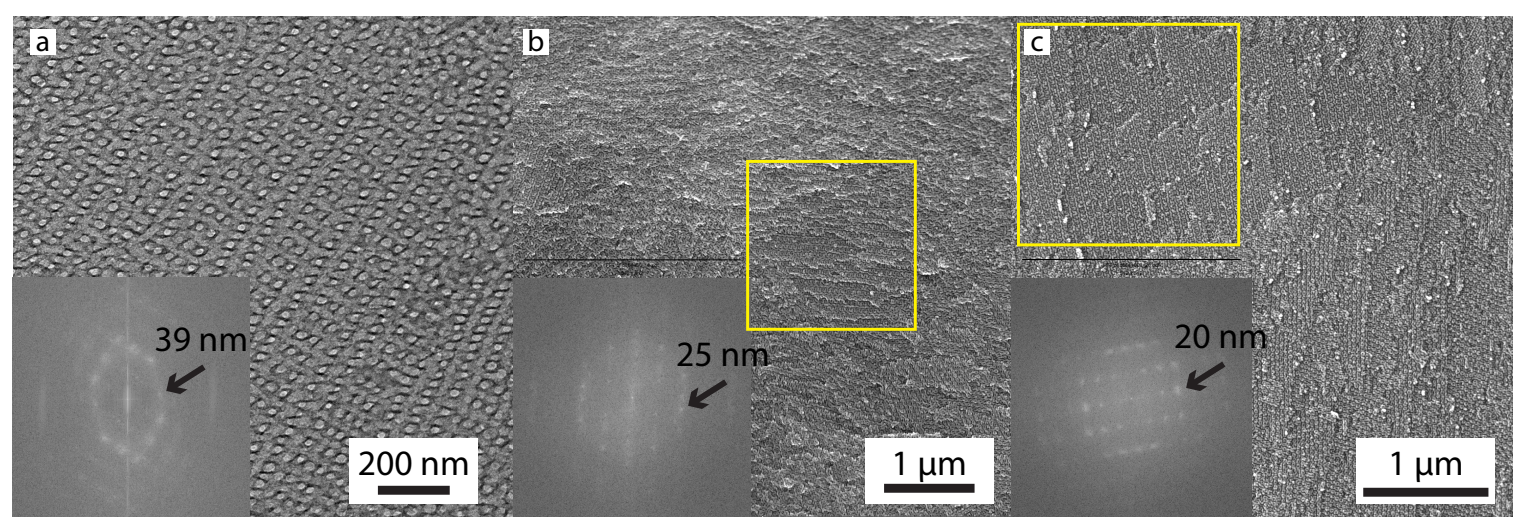

Figure S3. Electron microscopy results on PMVS/ISA samples exposed to a maximum temperature of 130 ${ }^{\circ} \mathrm{C}(\mathrm{a}), 450{ }^{\circ} \mathrm{C}(\mathrm{b})$, and $1000^{\circ} \mathrm{C}$ (c) and examined by TEM (a) and SEM (b-c). Insets show 2D fast-Fourier transforms of the entire image (a) or the yellow regions (b-c) with well-defined (211) "double wavy" surfaces. In (a) sample preparation by cyro-ultramicrotome has distorted the sample such that the FFT inset is very elliptical. 


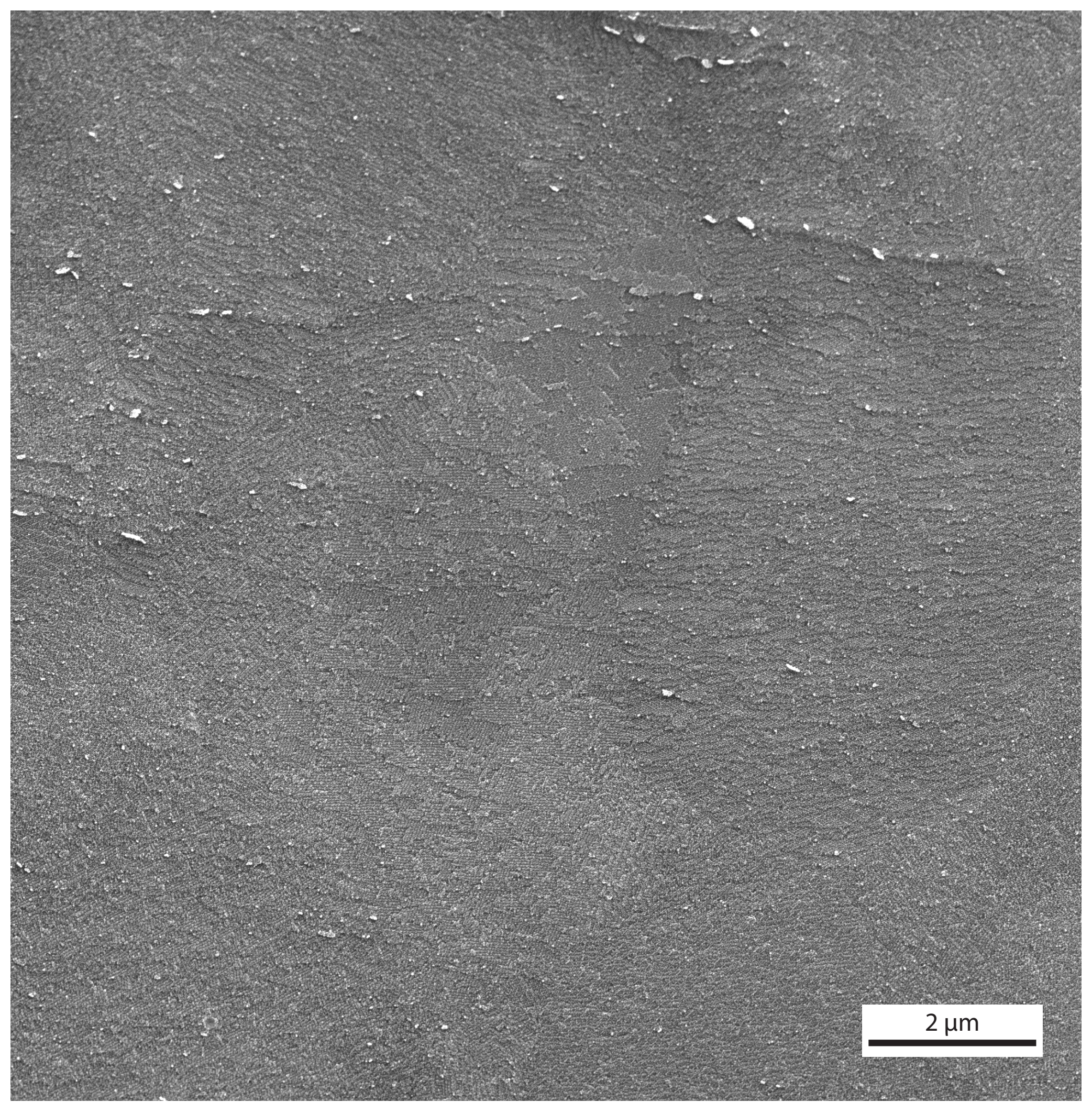

Figure S4. Low magnification SEM image of a fractured surface of mesoporous gyroidal silicon oxynitride (processed to a temperature of $1000{ }^{\circ} \mathrm{C}$ ) displaying mesoscale grains several microns in diameter. Grain boundaries appear both coherent and crack-free. 


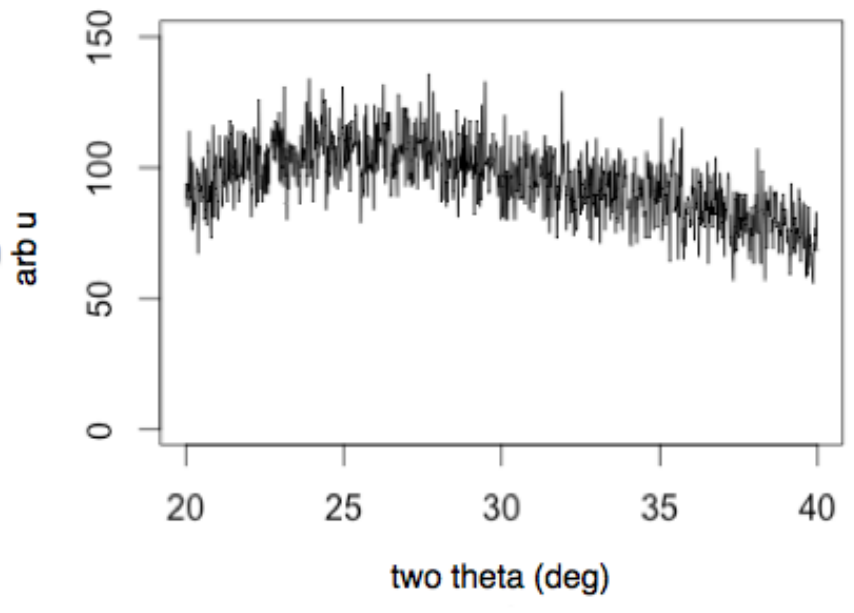

Figure S5. X-ray diffraction data showing $2 \theta$ values from $20^{\circ}$ to $40^{\circ}$ for powdered sample of mesoporous gyroidal PMVS/ISA processed to $1000^{\circ} \mathrm{C}$. XRD pattern was obtained using a Scintag Theta-Theta X-ray diffractometer with $\mathrm{Cu} \mathrm{K}$-alpha radiation $(40 \mathrm{kV}, 40 \mathrm{~mA}$, wavelength $1.5405 \AA)$ in a $2 \theta$ range between $20^{\circ}$ and $40^{\circ}$ with a speed of $1.2 \mathrm{~K} \mathrm{~min}^{-1}$ and a step size of $0.02^{\circ}$.

S6 Calculation of silicon oxynitride fractional pore volume (porosity):

Let:

$$
\begin{gathered}
v=\text { specific pore volume }=0.416 \frac{\mathrm{g}}{\mathrm{cm}^{3}} \\
e=\text { void ratio }=\frac{\text { volume occupied by free space }}{\text { volume occupied by ceramic phase }} \\
\varnothing=\text { porosity }=\frac{\text { volume occupied by free space }}{\text { volume occupied by free space }+ \text { volume of ceramic phase }} \\
\rho=\text { density of ceramic phase } \\
\varnothing=\frac{e}{1+e}=\frac{v * \rho}{1+v * \rho}
\end{gathered}
$$

\section{Additional Methods:}

Gel permeation chromatography. The number average molar mass of the polyisoprene block was calculated by gel permeation chromatogray (GPC) using a Waters Ambient-Temperature GPC with tetrahydrofuran as the solvent. ${ }^{1} \mathrm{H}$ NMR was used in conjuction with the poly(isoprene) number-average molar mass to calculate to total molar mass of the ISA terpolymer, $\mathrm{M}_{\mathrm{n}}=57 \mathrm{kDa}$. GPC was used to determine the polydispersity index (PDI) of the ISA terpolymer, $\mathrm{PDI}=1.11$, using polystyrene standards.

Proton NMR. The composition of the triblock terpolymer was determined using ${ }^{1} \mathrm{H}$ nuclear magnetic resonance $\left({ }^{1} \mathrm{H}\right.$ NMR) spectroscopy in conjunction with GPC. The polymer was dissolved in deuterated chloroform (chloroform-d, 99.8 atom \% D, Aldrich) to provide a concentration of $15-20 \mathrm{mg} / \mathrm{mL} .{ }^{1} \mathrm{H}$ NMR spectrum was recorded by 
averaging 8 spectra on a Varian Mercury $300 \mathrm{MHz}$ spectrometer collected with a $90^{\circ}$ pulse angle and 25 second relaxation time.

Electron microscopy. Transmission electron microscopy of $130^{\circ} \mathrm{C}$-treated polymer - ceramic precursor composite films were prepared by cryo-ultramicrotoming to a thickness of 60-80 $\mathrm{nm}$ using a Leica Ultracut UCT cryo-ultramicrotome equipped with a diamond knife at $-60{ }^{\circ} \mathrm{C}$. The microtomed sections were floated on a water/DMSO (40:60 vol) mixture and subsequently placed on copper grids. Contrast was obtained by the inherent difference in electron densities between the polymer blocks. Bright-field transmission electron microscopy was performed on a FEI Tecnai T-12 TWIN TEM operating at an accelerating voltage of $120 \mathrm{kV}$ equipped with a high-resolution, thermoelectrically cooled Gatan Orius dual-scan CCD camera.

Scanning electron microscopy of samples treated to ultimate temperatures of 450 ${ }^{\circ} \mathrm{C}$ and $1000{ }^{\circ} \mathrm{C}$ was carried out on a TESCAN MIRA3 LM FE-SEM operating at an accelerating voltage of $5 \mathrm{kV}$. Samples were coated with $\mathrm{Pd} / \mathrm{Au}$ prior to imaging for 20 seconds at 30-40 mA.

Small Angle X-ray Scattering. For SAXS measurements, small squares of the cured composites and pyrolyzed films (ca. $4 \mathrm{~mm}^{2}$ ) were cut and placed in the hole of a metal washer that was covered on one side with Kapton tape. SAXS measurements were performed at station G1 of the Cornell High Energy Synchrotron Source (CHESS). The sample to detector distance was $2.3 \mathrm{~m}$, and the X-ray wavelength was $1.2473 \AA$. The scattering vector $\mathrm{q}$ is defined as $\mathrm{q}=(4 \pi / \lambda) \sin \theta$, where $\theta$ is half of the scattering angle.

Infrared Spectroscopy. Fourier Transform Infrared Spectroscopy was performed using a Bruker Hyperion ® FT-IR spectrometer in attenuated total reflectance mode (ATR-FTIR) using a ZnSe crystal. Samples were ball-milled for 20 minutes prior to analysis.

Solid-state NMR. ${ }^{29} \mathrm{Si}$ cross-polarization / magic angle spinning $\left({ }^{29} \mathrm{Si} \mathrm{CP} / \mathrm{MAS}\right)$ NMR spectrum for mesoporous gyroidal silicon oxynitride sample processed to $1000{ }^{\circ} \mathrm{C}$ was recorded on a 9.4 T Bruker Avance DSX NMR spectrometer (Larmor frequencies: ${ }^{1} \mathrm{H}=400.23 \mathrm{MHz},{ }^{29} \mathrm{Si}=79.51 \mathrm{MHz}$ ) spinning the sample at $7 \mathrm{kHz}$ in a rotor of $4 \mathrm{~mm}$ diameter. ${ }^{1} \mathrm{H}$ spin lattice relaxation times, $\mathrm{T}_{1}$, were determined by inversion recovery experiments resulting in an experimental repetition delay of $3.5 \mathrm{~s}$ (five times the $1 \mathrm{H}$ relaxation times). The spectrum was acquired using cross-polarization with a $5 \mathrm{~ms} \mathrm{CP}$ contact time and TPPM decoupling. The spectrum was recorded over 2 hours (2048 transients). The chemical shift scale was referenced against the center of kaolin as secondary reference relative to TMS.

$X$-Ray Photoelectron Spectroscopy. Photoemission spectra for elemental analysis were acquired using a Surface Science Instruments SSX-100 with operating pressure of $\sim 2 * 10^{-9}$ Torr. Monochromatic Al K-alpha X-rays $(1486.6 \mathrm{eV})$ were used with beam diameter of $1 \mathrm{~mm}$. Photoelectrons were collected at a $55^{\circ}$ emission angle. A hemispherical analyzer determined electron kinetic energy, using a pass energy of $150 \mathrm{~V}$. A flood gun was used for charge neutralization because samples were insulating. Sample cleaning was performed using a $4 \mathrm{kV}$ Ar ion sputterer with a beam current of $1 \mu \mathrm{A}$ over an area of $2.5 \mathrm{~mm} \times 4 \mathrm{~mm}$ for 15 seconds to remove possible surface contaminants.

Nitrogen Sorption. Nitrogen adsorptions-desorption isotherms of the gyroidal mesoporous oxynitride material (processed to $1000{ }^{\circ} \mathrm{C}$ ) were recorded using a Micromeritics ${ }^{\circledR}$ ASAP 2020 following the Brunauer-Emmett-Teller (BET) method. Barrett-Joyner-Halenda (BJH) analysis was conducted employing a cylindrical pore model. 


\section{Supporting Information References}

(1) Schmidt, W. R.; Marchetti, P. S.; Interrante, L. V; Hurley, W. J.; Lewis, R. H.; Doremus, R. H.; Macielt, G. E. Ammonia-Induced Pyrolytic Conversion of a Vinylic Polysilane to Silicon Nitride. Chem. Mater. 1992, 7, 937-947.

(2) Scarlete, M.; McCourt, N.; Butler, I. S.; Harrod, J. F. Spectroscopic Investigation of the Synthesis of Thin Silicon Nitride Films on Silicon Single-Crystal Wafers via Ammonia-Assisted Pyrolysis of Organosilicon Polymers. Chem. Mater. 2001, 13, 655-661.

(3) Choong Kwet Yive, N. S.; Corriu, R. J. P.; Leclercq, D.; Mutin, P. H.; Vioux, A. Thermogravimetric Analysis/mass Spectrometry Investigation of the Thermal Conversion of Organosilicon Precursors into Ceramics under Argon and Ammonia. 2. Poly(silazanes). Chem. Mater. 1992, 4, 1263-1271.

(4) Burns, G. T.; Chandra, G. Pyrolysis of Preceramic Polymers in Ammonia: Preparation of Silicon Nitride Powders. J. Am. Ceram. Soc. 1989, 72, 333-337. 